\title{
The Problems and Countermeasures of the E-commerce Enterprise Internal Audit Informationization
}

\author{
Hu Xiaoqing, Zhang Chengqian \\ Shandong University of Science and Technology 271019 \\ Shandong University of Science and Technology271019
}

\begin{abstract}
Keywords: audit informationization, internal audit, audit resources, audit staff, e-commerce enterprise.
\end{abstract}

\begin{abstract}
E-commerce enterprise in China has been involved in various industries, its financial activities has the characteristic of paperless trading, complicated financial information processing, etc, the traditional manual audit technology has been unable to meet the demand of e-commerce enterprise internal audit. In view of the problems business enterprise internal audit informatization faced: the unbalance of regional informatization basic device configuration, the uncoordinated of hardware and software setup, the lack of technical specialist, this paper puts forward relevant measures to perfect the construction of informatization of e-commerce enterprise internal audit, such as to improve the importance understanding of internal audit informatization construction, to cultivate the compound audit talents who can meet the requirements of internal audit informatization, to perfect the internal audit organization, technology and the allocation of audit resources.
\end{abstract}

\section{Introduction}

In the late 1990s, science and technology, especially the rapid advance of computer network technology, brings great challenge to the traditional enterprise development. Under the development of internet information, business enterprise transaction cost is not high, and has high operation efficiency, and this business model is the e-commerce enterprise. With the rapid development of Internet information technology, e-commerce enterprises generally use the Internet, database, computer and other modern science and technology to implement the internal operation management, the internal control management activities become increasingly informatization. Internal management information can help e-commerce enterprise to convert the internal audit organization form, optimize the audit resources, and reform the auditing method, but at the same time, informationization has put forward more requirements to the internal audit of the e-commerce enterprise. Therefore, clearing the problem of the development of e-commerce enterprise internal audit informationization, widening scientific management experience of e-commerce enterprise internal audit informationization, further exploring the idea of the development of e-commerce enterprise internal audit informationization, finding out strategies to solve the difficulties, these will have certain practical guiding value to promote the development and innovation of e-commerce enterprise internal audit in our country.

\section{The new characteristics of financial activity of e-commerce enterprise}

The first characteristic is trading paperless. If an enterprise to develop and build strong vitality of the electric system, it needs to establish an information network platform based on Internet technology for business, financial cooperative development; and effectively manage the information of financial activities of enterprise needed, which is the prerequisite for e-commerce enterprise development. The business management activities of the implementation of information and data communication, is the business process reengineering based on Internet technology, so as to realize the development of enterprise's operation networking and digitalization. And the financial management activities of the e-commerce enterprise is a management model, which is under the background of Internet technology to realize enterprise financial paperless trading, the paperless 
trading pattern is e-commerce enterprise a new financial activities feature in the development, it gradually replaced the traditional trading patterns of the e-commerce enterprise. Customers transmit the required information data to the entire system of e-commerce enterprise supply chain on time, the buying and selling of the trading activities are generally occur at the same time, reduces the chance of time delay, realize zero time of waiting in theory. That really reveals the business philosophy of customer centered, at the same time, the financial activities of enterprises and e-commerce business are perfect fusion, and finally realize the high energy, precision and the electronic development of e-commerce enterprise financial activities.

The second characteristic is complicated financial information processing. In the traditional market situation, the enterprise financial business includes two parts of financial relations and the financial activities, specifically it can be divided into financing, investment and financing activities. In the situation of electric market, the e-commerce enterprise is an important node of the supply chain network system, and financial activities from the traditional financial relation and the financial activity transforms into the collaborative development of business and finance, enterprise financial activities will be fully integrated into the commodity production and marketing chain, the all financial activities of enterprise will be achieved through the network, such as commodity trading activities, the system sales settlement activities, network advertisement, and the use of electronic money to complete the payment network and other activities. Due to the change of environment of e-commerce enterprise financial activities, traditional financial accounting and financial valuation, traditional financial management and financial control also changed, all of these changes will be integrated into the whole enterprise financial activities; traditional information processing activities will become part of the financial activities of e-commerce enterprise, the object of e-commerce financial activities will be converted from the former capital activities into information management activities in the entire supply chain. These changes will expand the scope of the e-commerce enterprise finance information management in a certain extent, which lead to the complicated financial information processing.

\section{The problems of the e-commerce enterprise internal audit informationization}

\subsection{The unbalance of regional informatization basic device configuration}

From the geographical sense, the regional informatization basic device configuration of e-commerce enterprise is unbalance. In the developed regions of domestic economy, conditions of capital, technology are relatively perfect, therefore, the informatization of equipment in this region is relatively complete, and in underdeveloped areas, various information configuration conditions are subject to capital and technology; In the areas of central enterprises focused, the internal audit information management attention degree is high, thus the basis of information equipment configuration is also perfect; In the areas of the large and medium-sized state-owned enterprises focused, the basic information of equipment configuration more perfect. The e-commerce enterprises of the above article, either in hardware conditions or in software equipped, or information management professionals, is more perfect, and some e-commerce enterprises can even independent research and development the dedicated internal audit information management software, at the same time, can also implement internal information remote auditing or network audit. And in the regional where informatization equipment configuration is imperfect, because of the constraints in manpower, material and financial resources, the existing internal audit methods is artificial audit, some corresponding facilities construction is still in the initial stage, the e-commerce enterprise internal audit based on Internet, simply carry out some data printing and data processing work.

\subsection{The uncoordinated of hardware and software setup}

At this stage, the software and hardware settings of e-commerce enterprise internal audit work and the development of informationization are not coordinated, and there is "more attention hardware than software". Some domestic e-commerce enterprises have increased investment of 
audit informationization management; at the same time also have added the hardware settings of internal audit informationization. Some business leaders think once the internal audit organization configure computer equipment, the internal audit informationization work of enterprise has been done, this view ignores the human resources construction, enterprise informationization of internal audit work, that will lead lower using rate of information and Internet data, there is no effective to use the function of software of information technology, such as information collection, data sorting, data induction and data analysis, and then leads to the lower efficiency and lower quality of e-commerce enterprise internal audit informationization management.

\subsection{The lack of technical specialist}

At present, in the work process of e-commerce enterprise internal audit, lacks of composite personnel who knows both professional technical knowledge and knows how to audit work. But many enterprises internal audit staffs began to engage in the internal audit information management after learning and training. These training work basically is imparting basic knowledge about computer soft management, such as word management, software control and the production of forms, plus the effect of short learning time and training mode single, causing the related staff after trained still cannot effectively carry out internal audit information management work. In addition, the internal audit software update frequency fast, and after updating, some of the features of is changed, make the theory knowledge of some staff learned gradually out of date, and has no use. These phenomena seriously hinder the efficiency of e-commerce enterprise internal audit informationization management. The focus of network information audit work is not the account set data and data report, during the audit the date of internal staff using is the regeneration of the data, and is the middle table of internal audit data table. If professional software managers are not familiar with the audit theory knowledge, an effective combination of people and machine cannot achieve. Therefore, in the process of e-commerce enterprise internal audit informationization management, need a number of talents who both understand audit theoretical knowledge and understand the control technology of information software, only do this, the e-commerce enterprise can be widely carry out internal audit informationization.

\section{The improving countermeasures of the e-commerce enterprise internal audit Informationization}

\subsection{To improve the importance understanding of internal audit informatization construction}

To improving the e-commerce enterprise internal audit informationization, it needs to vigorously promote the important significance of internal audit informatization construction, and improve the importance understanding of internal audit informationization construction in all departments. First of all, correctly understand the development status and the development predicament of internal audit informationization construction of our country, and understand the gap between internal audit informationization construction and accounting computerization, networking, and audit work informationization of government information. Secondly, with the help of magazines, newspapers and other propaganda way to reinforce the importance of audit work, help the e-commerce enterprise managers and staff aware of the specific content and the significance of carrying out the internal audit of informatization construction, the measures for the implementation and teach them to make internal audit informatization construction, teach them the measures for the implementation of internal audit informatization construction. Again, make the related staff aware of no internal audit informatization construction, and the entire e-commerce enterprise will face the risk of loss of audit qualification; Internal Audit Management Association needs further to strengthen the management and supervision of e-commerce enterprise internal audit informationization construction, work out the Chinese characteristics outline of the internal audit informatization construction, increase the theoretical research of e-commerce enterprise internal audit informatization construction, and speed up the pace of development of e-commerce enterprise internal audit informatization construction. 


\subsection{To cultivate the compound audit talents who can meet the requirements of internal audit informatization}

The improvement of e-commerce enterprise internal audit informationization construction is inseparable from compound talents, who not only understand the audit business but also knows technical knowledge. First of all, from the enterprise perspective, to cultivate the compound talents of audit informationization, e-commerce enterprises need to strengthen the professional and technical knowledge of training audit staff. Under the premise of long-term education and short-term training, in-service training and follow-up training, the e-commerce enterprise internal audit institution need to combine its own development, implement the flexible training mode of the "to go out, bringing in". On the basis of the election principle about less what, what to teach; use what, what to repair, the e-commerce enterprise should start audit training in purpose, at the same time in accordance with the audit knowledge and information level of audit staff, using multi-layer education training; Secondly, from the perspective of educational institutions, domestic colleges and universities need to take audit and financial accounting professional as required courses of the construction of informationization of e-commerce enterprise internal audit informationization construction, to strengthen the information technology professional theory on college students education; Once again, from the auditor's perspective, the personnel of e-commerce enterprise internal audit informationization construction needs to establish lifelong learning concept, enhance innovation ability and application ability of information technology, and gradually adapt to the demands of enterprise internal audit information construction.

\subsection{To perfect the internal audit organization, technology and the allocation of audit resources}

In order to better manage the e-commerce enterprise internal audit informationization work, we need to further perfect the internal audit organization, technology and the allocation of audit resources. First, the government should perfect the relevant laws and regulations of e-commerce enterprise internal audit informationization construction, clearly define the organization mode of e-commerce enterprise internal audit informationization system, at the same time the audited enterprise should positive cooperate and assist. The enterprise needs to formulate the construction norm of e-commerce enterprise internal audit informationization, to eliminate the risk information security of e-commerce enterprise internal audit informationization management; Secondly, to further improve the e-commerce enterprise internal audit informationization construction, implement automation management in the audit office system, and improve the quality and efficiency of internal audit informationization construction. Positively develop the enterprise internal audit software, in addition to continue to improve the internal audit technology in data analysis, data query, information sharing and other functions, also need further to innovate audit technique. Once again, rational allocate the e-commerce enterprise internal audit resources. Establishing the integrated management platform of internal audit resources, which divided into these modules of specific financial resources, sales of goods and materials, production analysis, risk warning management, to realize the real-time allocation and efficient comprehensive analysis under the resource network, to the promote reasonable arrangements of enterprise internal audit resources, to better serve the development of the e-commerce enterprise.

\section{Conclusion}

The construction of information of e-commerce enterprise internal audit informationization, mainly help the business enterprise to search the optimal internal audit plan. Based on the characteristics of trading paperless and complicated financial information processing, this paper analysis the Problems of the e-commerce enterprise internal audit informationization, and from the importance, personnel training, organization, technology and audit resources etc, to discuss the improving countermeasures of the e-commerce enterprise internal audit Informationization construction. These lay the foundation for better internal audit work of the e-commerce enterprise, 
and have a certain guiding value.

\section{References}

[1] Fu Yuan-lue. Electronic commerce audit under the network environment. Journal of Jiangxi University of Finance and Economics, vol 03, pp.46-49, 2002.

[2] Sun Bao-wen, Li Hui. Study on risk management and audit of electronic commerce. Journal of Central University of Finance \& Economics, vol05, pp. 76-80, 2003.

[3] Li De-sheng, Zhao Jing. Enterprise internal audit under the information environment challenge. Audit \& Economy Research, vol04, pp.41-45, 2008.

[4] Wang bing, Bao Guo-ming. Experience of internal auditing practice and development of state owned enterprises. Auditing Research. vol 02, pp.76-81,2013.

[5] Zhong Hong-xia. Discussion on internal audit informatization -- Taking Jiangsu Telecom as an example. Communication of Finance and Accounting.vol 07, pp.98-100,2014. 